\title{
X VE Y KUŞAKLARININ İŞ DEĞERLERINİN KARŞILAŞTIRILMASI: TÜRKIYYE'DE BEYAZ YAKALILAR ÜZERİNDE BİR ARAŞTIRMA
}

\author{
A COMPARISON OF THE WORK VALUES OF X AND Y \\ GENERATIONS: A RESEARCH ON WHITE-COLLAR WORKERS IN \\ TURKEY
}

\author{
Selay GIRAY YAKUT ${ }^{*}$ iD \\ Müge Leyla YILDIZ ${ }^{* *}$ iD
}

\begin{abstract}
Özet
İş değerlerinde kuşak farklılıkları işe alma, eğitim ve geliştirme, kariyer gelişimi, ödül sistemi ve yönetim şeklini etkilemektedir. Yöneticilerin işletmelerde kuşak farklılıklarını en iyi ne şekilde yöneteceklerine dair önerilere ihtiyacı vardır. Dünyadaki kuşaklarla ilgili çalışmalar genellikle Kuzey Amerika'da ve Avrupa'da yoğunlaşmaktadır. Ancak kuşakların kültürlere göre farklılık gösterdiği bilinmektedir. Yabancı yazında yapılan bazı çalışmalar olsa da; kuşaklar çalışmalarının ülkelerin ve toplumların bölgesel ekonomik ve kültürel olaylardan etkilenerek gösterdiği farklılıklar nedeniyle, Türkiye'de yazından farklı sonuçlar elde edileceği beklenmektedir. Bu araştırmanın temel amacı, Türkiye'de X ve Y kuşaklarının iş değerleri açısından karşılaştırmalı şekilde analiz edilmesidir. Bunun yanısıra Türkiye'de işgücünün iş değerleri profilinin çıkartılması, iş değerlerinin kuşaklara ve cinsiyete göre karşılaştırılması da hedeflenmektedir. Çalışma kapsamında Tabakalı Örnekleme tekniğiyle tasarlanmış 949 birimlik bir örneklem ile çalışılmıştır. Kuşakların iş değerlerinin karşılaştırılmasında geniş örneklemle yapılan empirik bir çalışmadır. Anket yoluyla toplanan verilere uygulanan başlıca metotlar; geçerlilik ve güvenilirlik testleri yanı sıra Hotelling $\mathrm{T}^{2}$, Kolmogorov Smirnov, Box’s M, Mann Whitney U testi gibi çeşitli istatistiksel analiz teknikleridir. Analiz sonuçlarında ulaşılan bulgular karşılaştırmalı olarak yorumlanmıştır.
\end{abstract}

Anahtar Kelimeler: X kuşağı, Y Kuşağı, İș Değerleri, Uygulamalı İstatistik.

JEL Sinıflandırması : M12, M54, C10.

Abstract

Generational differences in work values influence recruitment training and development, career development, rewards and working arrangements, and management style. As a result of these supposed generational differences in workplace, managers need to advice on how best to manage generational

* Doç. Dr., Marmara Üniversitesi, İktisat Fakültesi, Ekonometri Bölümü, İstanbul, Türkiye. E-posta: selaygiray@marmara.edu.tr

** Doç.Dr., Marmara Üniversitesi, İşletme Fakültesi, İşletme Bölümü, İstanbul, Türkiye. E-posta: mlyildiz@marmara.edu.tr 
differences at work. Research in western countries proposed that young generations are more individualistic and prefer intrinsic work values such as work autonomy, work identity, challenging jobs, and self-expression. Most of the empirical research had conducted in North American society, however; there is little research on work values of Gen Y and Gen X in Turkey. The purpose of this paper was to compare the work values of the members of the generations and gender. It was also try to contribute to the Human Resources research field. Data were obtained from a survey of workers in Turkey $(n=949)$. This is a large-sample study that provides benchmark results for work values of millennial and X generations. Data were analyzed using various statistical techniques such as Hotelling $\mathrm{T}^{2}$, Kolmogorov Smirnov, Box’s M, Mann Whitney U Test etc. including reliability and validity analysis of the scale. Results of the study and implications are to be discussed.

Keywords: Generation X and Y, Work Values, Applied Statistics

JEL Classification : M12, M54, C10.

\section{Giriş}

İş değerleri çalışmaları çalışanların davranışlarının önem kazandığı son yıllarda oldukça araştırmaya konu olmuştur. ${ }^{1}$ İş değerleri işyerinde doğru ve yanlışın ne olduğunu ifade etmektedir. Başka deyişle iş değerleri, çalışanların işyerinde olması gerektiğini düşündüğü ve olmasını istedikleri çıktılardır. ${ }^{2}$ İş değerleri çalışanların çalışanın işe karşı düşünelerinin toplamı olarak tanımlanabilir. Çalışanların işe dair amaçlarını ifade ettiği gibi performansının, beklentilerinin ve motivasyonunun da önemli bir göstergesidir.

Günümüzde insan kaynağı hiç olmadığı kadar farklılaşmıştır. Kuşaklar bu işgücü farklılık nedenlerinden ve oldukça en ilgi çeken konulardan biridir. Çünkü kuşakların amaçlarının, beklentilerinin ve iş değerlerinin birbirinden farklılaştığına dair varsayım giderek daha iyi gözlemlenmekte ve deneyimlenmektedir. Ancak bu varsayım genelde popüler basında ve İnsan Kaynakları dergilerinde yer alırken az sayıda deneysel araştırmaya konu olmaktadır. Yöneticiler, insan kaynakları uzmanları ve araştırmacılar; iş hayatına giren yeni kuşakların nasıl yönetileceği konusuna ilgi duymaya başlamışlardır. ${ }^{3}$ Y kuşağı özellikle bilgi ve iletişim teknolojileri tabanlı sektörlerde ve işlerde kariyerinde ilerlemeye ve yönetici pozisyonlarına geçmiştir.

Y Kuşağı teknoloji içine doğmuş ve sosyal medyada gelişen her şeyden haberdardır. Ayrıca şirketlerin küçülmelerine de şahit olmuşlardır. ${ }^{4}$ Sonuç olarak şüpheci olup geleneksel hiyerarşi ve otoriteden hoşlanmazlar. ${ }^{5}$ Ayrıca ebeveynleri olan X kuşağından sıkı çalışma, eğitim gibi değerlerini bilir

1 Twenge, J.M., Campbell, S.M. (2012). Chapter 1: Who are the Millennials? Empirical evidence for generational differences in work values, attitudes and personality, Eddy S. Ng, Sean Lyons and Linda Schweitzer (2012). Managing the New Workforce International Perspectives on the Millennial Generation içinden.

2 Queiri, A. Wan Yusoff, W.F., Dwaikat, N. (2014). Generation-Y Employees' Turnover: Work-Values Fit Perspective, International Journal of Business and Management, 9(11): 199-213.

3 Cennamo, L., Gardner, D. (2008). Generational differences in work values, outcomes and person organization values fit, Journal of Managerial Psychology, 23(8): 891 - 906.

4 Loughlin, C., Barling, J. (2001). Young workers' work values, attitudes, and behaviours, Journal of Occupational and Organizational Psychology, 74: 543-558.

5 Munro, C.R. (2009). Mentoring Needs and Expectations of Generation-Y Human Resources Practitioners: Preparing the Next Wave of Strategic Business Partners, Journal of Management Research, 1(2):1-25; Martin, C., \& Tulgan, B. (2002). Managing the generation mix: From collision to collaboration. Amherst, MA: HRD Press. 
ve onların yaptıkları hataları yapmaktan kaçınır. ${ }^{6}$ Meier ve Crocker (2010) göre, ${ }^{7}$ Y kuşağı hedef odaklı, bağımsız, özgüvenli olup ve genelde öğretmenleri ve ailelerinden daha fazla dijital dünyayı kullanmaktadırlar. Bu kuşak için teknoloji; herkese, her yerde, her zaman ulaşabilmeleri anlamına gelmektedir. Değerler tutumları, tutumlar da davranışları etkilediği için eğer kuşakların farklı değer sistemleri varsa bu durumda çalışanlar bu değerlere göre tutum ve davranış geliştireceğinden bunları anlamak önemlidir. ${ }^{8}$ Ancak kuşak çalışmaları her ne kadar oldukça yararlı şekilde yaş gruplarına göre çeşitli profiller belirlese de genellebilirlik açısından bazı ciddi eleştiriler almaktadır. Yabancı yazında belirlenen kuşak özellikleri kültürlere, ülkelere, ekonomilere vb. göre çeşitli farklılıklar göstermektedir. Örneğin, her ne kadar teknolojik gelişim açısından benzer özelliklere sahip olsa da Çin'de yaşayan Y kuşağı mensubu ile Türkiye’de büyüyen ve iş hayatına atılan Y kuşağı mensubu farklı özelliklere sahiptir. Çünkü bu kuşakta internetin iş hayatlarında oldukça önemli bir unsur haline gelse de içinde bulundukları ekonomik, politik ve hatta sosyal farklılıklar bu kuşak çalışanlarını da ciddi oranda farklılaştırmaktadır. Bu durumda kuşak çalışmalarının her ülkenin kendi çalışan örnekleminde ampirik çalışma yapılmasının önemini vurgulamaktadır.

İş değerlerinde kuşak farklılıkları işe alma, eğitim ve geliştirme, kariyer gelişimi, ödül sistemi ve yönetim şeklini etkilemektedir. Yöneticilerin işletmelerde kuşak farklılıklarını en iyi ne şekilde yöneteceklerine dair önerilere ihtiyacı vardır. ${ }^{9}$ Türkiye’de kuşak karşılaştırmalarına bakıldığgnda küçük örneklemlerde ya da öğrenciler üzerinde yapılan çalışmalara rastlanmaktadır. Bu bağlamda bu araştırmanın temel amacı, Türkiye'de büyük örnekleminde X ve Y kuşaklarına mensup çalışanların iş değerleri açısından karşılaştırmalı şekilde analiz edilmesidir. Bunun yanısıra Türkiye’de iş değerlerinin cinsiyete göre farklılaşıp farklılaşmadığı, farklılaşıyor ise bu farklılığın yapısı da irdelenecektir. Böylece dolaylı olarak Türkiye'de işgücünün iş değerleri profili de (ana hatları ile) çıkartılması amaçlanmaktadır. İlk olarak ilgili yazındaki çalışmalar ele alınacak, yöntem ve analizlerden sonra sonuçlar ve öneriler tartışılacaktır.

\section{Kuşak Teorisi}

Geçmişte birçok kuşak bir arada aynı işletmede çalışmıştır. Ancak birbirlerinden farklı iş tanımları ve farklı bir sistem hiyerarşisi içerisindeydi. Orta yaş çalışanlar orta düzey yönetici olma eğilimdeydi, genç çalışanlar da geri kalan pozisyonlarda çalışmaktaydı. Bu kuşakların etkileşimleri de genellikle ast-üst ilişkisi şeklindeydi. ${ }^{10}$ Ancak teknolojinin gelişimi ile birlikte ihtiyaç duyulan yetkinliklerin değişimi yaşa ve kıdeme dayalı hiyerarşik sistemleri yeniden düzenledi. Farklı kuşaklarda birbiriyle hiç olmadıkları kadar farklı şekilde iletişim kurma ve birlikte çalışmaya başladılar.

6 Meier, J., Crocker, M. 2010. "Generation Y in the Workforce: Managerial Challenges", The Journal of Human Resource and Adult Learning, 6(1): 68-78.

7 Eisner, S. P. (2005). Managing generation Y, SAM Advanced Management Journal, 70(4): 4-1; Martin ve Tulgan, 2002.

8 Greenwood R.A., Gibson, J.W., Murphy, Jr. E.F. (2008). An Investigation of Generational Values in the Workplace: Divergence, Convergence, and Implications for Leadership, International Leadership Journal, 1(1): 57-77.

9 Parry, E., Urwin, P. (2011). Generational Differences in Work Values: A Review of Theory and Evidence, International Journal of Management Reviews, 13(1):79-96.

10 Cennamo ve Gardner, 2008. 
Günümüzde işletmeler üç hatta belki dört kuşağın birlikte çalıştığ 1 bir ortam haline gelmiştir. İnsan kaynakları yönetim stratejileri, stratejik önem taşıyan her yaştan/kuşaktan çalışanı iş başvurusu için çekme, işe başladıktan sonra bağlılık yaratma ve işte kalmasını sağlamayı amaç edinmektedir. Kuşak, benzer coğrafyada benzer sosyal olayları deneyimlemiş benzer yaş grubunda olan bir grup insanı ifade etmektedir. Kuşakların kapsadığı tarihler, kuşak sayıları ve hatta isimleri arasında dahi tartışmalar ve eleştiriler hala devam etmektedir. Kuşak (jenerasyon) teorisi insanların değerleri, tutum ve inançlarının değişimi kuşaklar arasındaki toplumdaki sosyal değişimler, önemli tarihsel olaylar ile açıklamaktadır. Strauss ve Howe’nin (1991) “Jenerasyonlar: Amerika’nın Geleceği, 1584-2069” isimli kitabıyla popüler olmuştur. Onlara göre sosyal döngüler her 4 kuşakta bir kendini tekrarlamaktadır. Kuşakların hangi yıllar arasında doğanları kapsadığı birçok kaynakta farklılık göstermektedir. En kabul gören şekilde kuşakların yaş aralıkları şu şekildedir: ${ }^{11}$

- Büyük Kuşak (great generation): 1901 ile 1924 yılları arasında doğan,

- Sessiz Kuşak (silent generation): 1925 ile 1945 arasında doğan,

- Bebek Patlaması Kuşağı (baby boom ya da baby boomers): 1946-1969 yıllarında doğan,

- X Kuşağ1 (generation X ya da baby busters): 1970’lerde ve 80’lerin başında doğan,

- Y Kuşağ1 (generation Y, millennials, next generation, echo boomers): 1981'den milenyumun (başka deyişle 2000'li yılların) başına kadar doğan ve

- Z Kuşağ1 (generation Z, internet generation, generation @): 2000’li yıllardan günümüze kadar doğan çocukların oluşturduğu kuşaktır.

Z kuşağı henüz yeni yeni üniversitelere öğrenci olarak giriş yapmaktadır. Birkaç yıl içerisinde Z kuşağı doğumlu örneklemler üzerinde çalışmalar görülecektir. Y kuşağı; hedef odaklı, bağımsız, özgüvenlidirler ve genelde öğretmenleri ve ailelerinden daha fazla dijital dünyayı kullanmaktadırlar. Onlar için teknoloji herkese her yerde her zaman ulaşabilmeleri anlamına gelmektedir. ${ }^{12} \mathrm{H}$ ız çağında büyüyen Millenyumlar ise "her şeyi ve hemen isterler". Başka deyişle; iyi bir ücret ve yan haklar, hızlı yükselme, iş-aile dengesi, ilginç ve zorlayıcı bir iş ve topluma fayda sağlamayı istemektedirler. ${ }^{13}$ Y kuşağı hayatlarının çok yönlülüğü içinde aynı anda birden fazla işi yaparak büyüdü. Okuldan spora, internete bir görevi rahatlıkla aynı anda yapabilir. Hızlıca görevleri tamamlayıp bir sonrakine geçebilir ve iş hayatına girdiğinde sorumluluk almaya hazırdır. Durup yöneticinin onlara görev vermesini beklemezler. ${ }^{14}$ Kariyerlerini ön plana alan X kuşağı yerine Y kuşağı iş-aile dengesine önem

11 Saruhan,S.C., Yıldız, M.L. (2018). İnsan Kaynakları Yönetimi, 3.Baskı, Beta:İstanbul.; Zemke, R., C. Raines, B. Filipczak 1999. Generations at Work: Managing the Clash of Veterans, Boomers, Xers, and Nexters in Your Workplace, Amacom.

12 Meier ve Crocker, 2010; Eisner, S.P. (2005). Managing generation Y, SAM Advanced Management Journal, 70(4): 4-15; Martin and Tulgan, 2005.

13 Ng, E.S.W., Schweitzer, L., Lyons, S.T. (2010). New Generation, Great Expectations: A Field Study of the Millennial Generation, Journal of Business and Psychology, Special Issue: Millennials and the World of Work: What You Didn't Know You Didn't Know, 25(2): 281-292. 
vermektedir. ${ }^{15}$ Kariyer açısından da önceki kuşağa göre farklı bir kariyer yönetimi, kariyer planlama anlayışı söz konusudur. ${ }^{16}$

X kuşă̆ı; ebeveynlerinin hatalarından nasıl kaçınacağını öğrendi ve eğitime, sıkı çalışmaya ve paranın gücüne değer veren bir kuşak içinde büyüdü. ${ }^{17}$ Kariyerlerinin uzun soluklu olacağ1 ve çok çalışma gerektireceğini düşünürler. Ayrıca ebeveynleri kadar işkolik değillerdir ama iyi bir hayat yaşamak için çok çalışmaları gerektiğini bilirler.

\subsection{Türkiye'de X ve Y Kuşaklarının İş Değerleri}

Genel değerler ve iş değerleri farkı arasındaki tartışmalar devam etse de iş değerleri "çalışanların çalışırken hissettikleri ya da istedikleri çıktılar” olarak tanımlanabilir. İş değerleri çalışanların işe karşı algılarını, davranış ve tutumlarını ve iş seçimlerini de etkilemektedir. ${ }^{18}$ İş değerlerine dair farklı sınıflandırmalar mevcuttur: İçsel büyüme, dışsal büyüme, kavrama ilişkin, üretkenlik ile ilgili (boş zaman, güvenlik, sağlık, stabilite), duygusal (ilginçlik, sosyal etkileşim vb.) iş değerleri, ${ }^{19}$ İçsel, dişsal, boş zaman, etik ve sosyal değerler ${ }^{20} \mathrm{vb}$. bazı sınıflandırmalar yer almaktadır. Bu çalışmada genel olarak kabul gören aşağıdaki sınıflandırma ele alınmmıştır: ${ }^{21}$

Dişsal (extrinsic/instrumental) iş değerleri: Dışsal iş değerleri dişarıdan gelen ve bireysel somut ödül olarak adlandırılan çıktıları ya da sonuçları ifade ederler. Bu nedenle dışsal ödüller (extrinsic rewards) olarak adlandırılmaktadır. Bu gruptaki değerler; gelir, yan haklar, iş güvencesi vb. şeklinde siralanmaktadir.

İçsel (intrinsic/cognitive) iş değerleri: Dişsal iş değerlerinin tam tersi olan işte öğrenme potansiyeli, yaratıcı olma firsatları gibi soyut ödülleri içeren iş süreçlerine odaklanan değerler içsel iş değerleri olarak adlandırılmaktadır. Entelektüel uyarılma, ilginçlik, çeşitlilik gibi değerler bu gruptadır.

Özgürlük (freedom) ya da Boşzaman (Leisure) ile ilgili değerler: Y ve X kuşakları yaşamak için çalışırken Bebek patlaması kuşağı çalışmak için yaşama anlayışına sahiptir. Çalışma saatleri, yalnız çalışma vb. değerler bu gruptadır.

Sosyal (social) değerler: Y ve X kuşakları yaşamak için çalışırken Bebek patlaması kuşağı çalışmak için yaşama anlayışına sahiptir. Çalışma saatleri,

15 Daft, R.L. (2007). Management, The Dryden Press, 10.Baskı.

16 Meier ve Crocker, 2010; Munro, 2009.

17 Meier ve Crocker, 2010.

18 Twenge ve diğerleri, 2010.

19 Hertel, G., Thielgen, M., Rauschenbach, C., Grube, A., Stamov-Roßnagel, C. and Krumm, S.(2013), Age Differences in Motivation and Stress at Work', in C. M. Schlick, E. Frieling, and J. Wegge (eds), Age-Differentiated Work Systems (Heidelberg: Springer-Verlag), pp. 119-47.

20 Twenge ve diğerleri, 2010; Twenge, 2010.

21 Twenge ve diğerleri, 2010; Lyons, S.L. Duxbury, C. Higgins (2005). An empirical assessment of generational differences in work-related values, Human Resource Management, 26: 62-71; Ryan, R. M., Deci, E.J. (2000). Self-determination theory and the facilitation of intrinsic motivation, social development, and well-being. American Psychologist, 55: 6878. 
Etik (alturistic) ile ilgili değerler: Toplumdaki diğer insanlara yardım etmeye dair değerleri kapsar. Genelde Y kuşağının X’den daha duyarlı olduğu öne sürülmektedir.

Kuşaklar özelinde yapılan çalışmaları ele almadan önce iş değerlerinin yaşa göre farklılaşıp farklılaşmadığını inceleyen çalışmaları irdelemekte fayda vardır. Cherrington, Condie ve England (1979), ${ }^{22}$ çalışan yaşının iş değerleri üzerindeki etkisini incelemeye yönelik yürüttüğü araştırma sonucunda yaşı büyük çalışanların işin ahlaki yönüne; genç çalışanların ise para, iş arkadaşlığı gibi konulara önem verdiği sonucuna ulaşmışlardır. Çalışanların yaşlarına bağlı olarak iş değerlerinin farklılaşmasının nedenini kişinin zamanla yaşadığı deneyimlerin artmasıyla bakış açısının değişmesi olarak görmektedirler. Li, Liu ve Wan $(2008)^{23}$ tarafından yürütülen bir araştırma sonucunda da benzer sonuçlar elde edilmiş ve iş değerlerine yönelik algının yaşı büyük çalışanlarda genç çalışanlara göre daha yüksek olduğu sonucuna ulaşılmıştır.

Kuşaklar teorisi doğrultusunda, farklı politik ve sosyal olaylar içerisinde yetişmiş olmakla birlikte farklı değer, inanç ve kişiliklere sahip olan X ve Y kuşak mensubu bireyler, aynı çalışma ortamı içerisinde birbiriyle etkileşim halinde çalışmaktadırlar. Farklı kuşakların iş yaşamında bir arada çalışması bazı yönetsel problemleri de beraberinde getirmektedir ve bu çeşitliliğin yönetilebilmesi noktasında önce kuşaklar arası farklılık ve benzerliklerin ortaya konması önemlidir. Literatür incelendiğinde iş yaşamında yer alan kuşakların benzerliklerini ve farklılıklarını anlamaya yönelik birçok çalışma olmasına rağmen bulgular bazen kafa karıştırıcı olabilmektedir.

$\mathrm{X}$ ve $\mathrm{Y}$ kuşakları arasındaki yaşam tarzı, tutum ve inanç farklılıkları düşünüldüğünde işe dair değerlerinin de farklı olması olasıdır. Literatür incelendiğinde iş değerleri ile kuşaklar arasındaki ilişkiyi konu edinen çalışmaların kısıtlı olduğu ve iş değerlerinin kuşaklara göre farklılaşıp farklılaşmadığ ${ }_{1}$ sorusuna verilen cevapların değişken olduğu görülmektedir. İş değerleri ile kuşaklar arasında anlamlı bir ilişkinin olmadığı sonucuna ulaşılan çalışmalar ${ }^{24}$ mevcut olmasına rağmen özellikle Türkiye örnekleminde iş değerlerinin kuşaklara göre farklılaştığ s sonucuna ulaşılan çalışmalara da rastlanılmaktadır. ${ }^{25}$

22 Cherrington, D.J., Condie, S.J., \& England, J.L. (1979). Age Work Values. Academy of Management Journal, 22(3), 617623.

23 Li, W., Liu, X., \& Wan, W. (2008). Demographic Effects Of Work Values And Their Management Implications. Journal of Business Ethics, 81(4), 875-885.

24 Sagie, A., Elizur, D., \& Koslowsky, M. (1996). Work Values: A Theoretical Overview and a Model of Their Effects. Journal of Organizational Behavior, 17(S1), 503-514; Furnham, A., Petrides, K. V., Tsaousis, I., Pappas, K. \& Garrod, D. (2005). A Cross-Cultural İnvestigation into the Relationships between Personality Traits and Work Values. The Journal of Psychology, 139(1), 5-32; Bayar, L. (2016). Demografik Faktörlerin İș Değerleri Üzerine Etkisi; İşçi Sendikaları Üzerine Bir Araştırma. Adnan Menderes Üniversitesi Sosyal Bilimler Enstitüsü Dergisi, 3(1), 38-67; Van Den Ouweland, L., \& Van den Bossche, P. (2017). The Impact of Values-Job Fit and Age on Work-Related Learning. International Journal of Training and Development, 21(3), 195-210.

25 Demirkaya, H., Akdemir, A., Karaman, E., \& Atan, Ö. (2015). Kuşakların yönetim politikası beklentilerinin araştırılması, İşletme Araştırmaları Dergisi, 7(1): 186-204, Süral-Özer, P., Eriş, E. D., \& Timurcanday-Özmen, Ö.N. (2013). Kuşakların Farklılaşan İş Değerlerine İlişkin Emik Bir Araştırma. Dumlupinar Üniversitesi Sosyal Bilimler Dergisi, 38(38), 123-142; Şenturan, Ş., Köse, A., Dertli, E., Başak, S., \& Şentürk, N. (2016). X ve Y Kuşağı Yöneticilerinin İş Değerleri Algısı ve Farkll1ıkları Üzerine İnceleme. Business \& Economics Research Journal, 7(3), 171-182. 
Türkiye çalışan örnekleminde iş değerlerinde kuşakların önem verdiği konular incelendiğinde; X kuşağı çalışanları para, yüksek bir statü, başarıya yönelik ödüllendirme ve takım çalışmasından ziyade bireysel çalışma gibi konuları daha ön planda tuttuğu görülmektedir. Y kuşağı çalışanları iş değerlerinde ise yaratıcılığın desteklenmesi, geribildirim, mesleki ve kişisel gelişim, kurumun imajı ve kurumun sosyal sorumluluk düzeyi, bilgiye ulaşılabilirlik gibi konuları ön planda tuttuğu görülmektedir. ${ }^{26} \mathrm{Y}$ kuşağı çalışanları başarıya yönelik ödüllendirmede kişiselleştirilmiş bir ödül sistemine değer vermektedirler ve önceki kuşaklardan farklı olarak kendilerini meslek ya da örgütler ile değil kişisel özellikleri ve başarıları ile özdeşleştirmektedirler. X kuşağı çalışanları işe saygı ve sadakat konusunda en zayıf kabul edilen kuşak iken; Y kuşağı çalışanları iş yaşamında en az katı olan kuşak olarak kabul edilmektedir. ${ }^{27}$

Şenturan ve arkadaşlarının (2016) ${ }^{28}$ yapmış olduğu çalışma sonucunda Y kuşağı yöneticilerin iş değerleri algılarında bazı boyutların X kuşağı yöneticilerine göre daha etkili olduğu sonucuna ulaşılmıştır. Farklılığın algılandığı boyutlar etkileme ve ilerleme, özerklik ve yeteneklilik, finansal koşullar/çalışma koşulları ve iş ilişkileri boyutlarıdır. Fernandes, Hyde, Ives, Fleischer, Evoy ve Marrum (2012) ${ }^{29}$ tarafından yapılan araştırma sonuçları incelendiğinde $\mathrm{Y}$ kuşağı çalışanlarının boş zamana X kuşağ fazla değer verdiği, ancak X kuşağı ile karşılaştırıldığında içsel ödüllere daha az değer verdiği görülmesine rağmen kuşaklar arası iş değerleri arasında anlamlı bir farklılı̆̆a rastlanılmamıştır.

Değerler tutumları tutumlar da davranışları etkilediği için eğer kuşakların farklı değer sistemleri varsa bu durumda çalışanlar bu değerlere göre tutum ve davranış geliştireceğinden bunları anlamak önemlidir. ${ }^{30} \mathrm{Bu}$ bağlamda Türkiye’de $\mathrm{X}$ ve y kuşak çalışanlar üzerinde geniş bir örneklemde iş değerlerini konu alan araştırmanın amaçları şu şekilde detaylandırılabilir:

- Türkiye'de X ve Y kuşak çalışanların iş değerleri profilinin çıkartılması,

- Türkiyede iş değerleri X ve Y kuşaklarında farklılaşıp farklışmadığının tespiti ve farklılaşmanın yönünün belirlenmesi,

- Türkiye’de iş değerleri cinsiyete göre değişiklik gösterip göstermediğinin belirlenmesidir.

\section{Yöntem}

Çalışmada nicel araştırma yöntemi kullanılmıştır. Veri toplama aracı olarak anket yöntemi kullanılmıştır. Anket yoluyla toplanan verilere uygulanan başlıca analiz yöntemleri; Güvenilirlik Analizi, Hotelling $\mathrm{T}^{2}$, Kolmogorov Smirnov Testi, Box’s M Testi, Mann Whitney U Testi gibi çeşitli istatistik teknikler ve testlerdir. İlgili tekniklerin uygulanmasında istatistik paket programlarından faydalanılmıştır.

26 Demirkaya ve diğerleri, 2015; Süral-Özer ve diğerleri, 2013.

27 Özer ve arkadaşları, 2013.

28 Şenturan ve diğerler, 2016.

29 Fernandes, K., Hyde, A., Ives, S., Fleischer, S., Evoy, T., \& Van Marrum, K. (2012). A Comparative Study of Work Values between Generation X and Generation Y. Unpublished manuscript, University of Guelph.

30 Greenwood ve diğerleri, 2008. 


\section{1. Örneklem}

Çalışmada tabakalı örnekleme kullanılmıştır. Alt örneklem hacimleri belirlenirken Orantılı dağıtım yöntemi kullanılmıştır. Türkiye’de [15-34] yaş grubunda çalışmakta olanların (Y kuşağı) oranı, [3544] yaş grubunda çalışmakta olanların (X kuşağı) oranından daha yüksektir. Örneklemde de oranlar arası bu ilişki korunmuştur. Ayrıca araştırma en büyük istihdam payına ait il olan İstanbul ve en fazla beyaz yakalı çalışan istihdam ettiren hizmet ve sanayi sektörleri ile sınırlandırılması uygun görülmüştür. Özetle amaç doğrultusunda çalışma kapsamında Tabakalı Örnekleme tekniğiyle tasarlanmış 35-44 yaş arasındaki çalışanlar X kuşağ $(\mathrm{N}=375)$ ve 15 ve 34 yaş arasındaki çalışanlar $\mathrm{Y}$ kuşağ 1 (N=574) olmak üzere toplamda 949 beyaz yakalı çalışandan oluşan İstanbul'da çalışan tesadüfi örneklem ile çalışılması hedeflenmiştir. Örneklem hacmi belirlenirken literatürde yapılan diğer benzer çalışmalar gözönünde bulundurulmuş, konu ile ilgili geliştirilmiş tablolardan yararlanılmıştır. Araştırmanın kısıtı ise bütçe ve zaman olmuştur.

Ankete katılan 949 kişiden \% 60,5’i Y kuşağından, \% 39,5’i X kuşağındandır. Katılımcıların \% 63’ü erkek, geri kalanı ise kadındır. Katılımcıların \% 90,8’i özel sektörde, geri kalanı kamu sektöründe çalışmaktadır. Ankete katılanların \% 77'si hizmet sektöründe, geri kalanı ise sanayi sektöründe istihdam edilmektedir.

\section{2. Ölçekler}

Araştırmada kullanılan ölçek; iş değerleri için Lyons (2005) tarafından geliştirilen soru formudur. Ölçekte yer alan değerlerden bazıları çeşitlilik, başarı, eğlence, iş güvenliği şeklinde sıralanmaktadır. "Başarılı olduğunuzu hissettiren işi yapmak, Dünyayı gezebileceğiniz bir işte çalışmak" ölçekte yer alan sorulara örnektir. Ölçekte $0=$ Hiç önemli değil, $7=$ Çok önemli anlamına gelmektedir. Ölçekte yer alan sorular için ortalamaların yaklaşık olarak 5 ve üstü şeklinde elde edildiği söylenebilir. Dolayısıyla ölçekteki her maddeye önem verilmektedir.

İstatistiksel analizlerde çeşitli testlerin başlıca varsayımı analiz kapsamındaki bağımsız değişkenlerin ilişkisiz olması nedeniyle öncelikle Faktör Analizi uygulaması ile iş değerleri konulu maddeler, ilişkisiz ve az sayıda yeni yapay değişkene dönüştürülmüştür. Araştırma kapsamında toplanan verilere geçerlilik ve güvenirlik analizleri doğrultusunda faktör analizi uygulanmıştır. Faktör analizi sonuçları ve her bir faktörün güvenilirlik düzeyi Tablo 1'de görülmektedir.

Tablo 1: İş Değerleri Faktör Analizi Sonuçları

\begin{tabular}{|l|c|l|l|}
\hline & İçsel değerler & Dişsal ve boş zaman/özgürlük ile ilgili değerler & Sosyal değerler \\
\hline Entelektüel Uyarılma &, 885 & & \\
\hline Çeşitllik &, 854 & & \\
\hline İlginçlik &, 803 & & \\
\hline Etkileme &, 733 & & \\
\hline Prestij &, 703 & & \\
\hline Yetenekleri Kullanma &, 699 & & \\
\hline Yaratıcılık &, 671 & & \\
\hline
\end{tabular}




\begin{tabular}{|c|c|c|c|}
\hline Ücret & & ,759 & \\
\hline Denge & & ,742 & \\
\hline İş Güvencesi & & 645 & \\
\hline Çalışma Saatleri & & ,617 & \\
\hline Yan haklar & &, 596 & \\
\hline Yalnız Çalışma & &, 506 & \\
\hline İş arkadaşları & & & 865 \\
\hline Eğlence & & & 819 \\
\hline Açıklanan varyans $\%$ & 28,644 & 19,820 & 12,497 \\
\hline Güvenilirlik katsayısı $(\alpha)$ & 0,813 & 0,754 & 0,804 \\
\hline
\end{tabular}

Türkiye’de beyaz yakalılar örnekleminde iş değerleri 3 faktörlü bir yapı göstermiştir. Faktörlerin Cronbach Alpha katsayılarına bakıldığında güvenilir olduğu görülmektedir. Ayrıca ölçek Türkçe ve İngilizce’ye çevrilmiş ve kapsam geçerliliğini sağlamak için akademisyen ve beyaz yakalı çalışan olmak üzere toplam 30 kişiye yüzyüze yapılarak anlam farklılıkları düzeltilmiştir. Bu bağlamda araştırmada kullanılan ölçek geçerli ve güvenilirdir.

Faktör analizi sonuçlarına bakıldığında, dışsal ve özgürlük ile ilgili iş değerleri birleşik bir yapı göstermiştir. Son faktör de iş arkadaşları ve eğlence değerlerini içeren sosyal iş değerkerinden oluşmaktadır.

\section{Bulgular}

Bu başlık altında Türkiyede beyaz yakalı çalışanların iş değerlerine genel olarak profili ele alınacak, kuşaklara ve cinsiyete göre iş değerleri analizleri yapılacak ve X ve Y kuşaklarının cinsiyete göre farklılık testleri analiz bulguları yer alacaktır.

\subsection{Türkiye'de Beyaz Yakalı İş Değerleri Genel Profili}

Araştırmada kullanılan maddelerin iş değerinin ortalama, medyan ve standart sapma değerleri Tablo 2’de görüldüğü gibidir:

Tablo 2: İş Değerlerinin Tanımlayıcı İstatistik Değerleri

\begin{tabular}{|l|c|c|c|c|}
\hline & $\mathbf{N}$ & Ortalama & Medyan & S.S. \\
\hline Başar1 & 949 & 6,30 & 7,00 & 1,157 \\
\hline Katk1 & 949 & 5,90 & 6,00 & 1,460 \\
\hline Otorite & 949 & 4,72 & 5,000 & 2,00 \\
\hline Yan Faydalar & 949 & 5,53 & 6,00 & 1,938 \\
\hline Özerklik & 949 & 6,14 & 7,00 & 1,342 \\
\hline Meydan Okuma & 949 & 5,26 & 6,00 & 1,829 \\
\hline Yetki & 949 & 5,86 & 7,00 & 1,576 \\
\hline Yaratıcilk & 949 & 5,83 & 6,00 & 1,462 \\
\hline Adalet & 949 & 6,40 & 7,00 & 1,347 \\
\hline
\end{tabular}




\begin{tabular}{|l|c|c|c|c|}
\hline Geri Bildirim & 949 & 5,66 & 6,00 & 1,561 \\
\hline Çalışma Arkadaşları & 949 & 5,92 & 7,00 & 1,517 \\
\hline Eğlence & 949 & 5,73 & 6,00 & 1,540 \\
\hline Sürekli Öğrenme & 949 & 6,09 & 7,00 & 1,336 \\
\hline Çalışma Saatleri & 949 & 6,10 & 7,00 & 1,408 \\
\hline Tek Başına Çalışma & 949 & 5,09 & 5,00 & 1,888 \\
\hline Etkilenme & 949 & 5,33 & 6,00 & 1,571 \\
\hline Entelektüel Uyarılma & 949 & 4,97 & 5,00 & 1,963 \\
\hline İlginçlik & 949 & 5,42 & 6,00 & 1,752 \\
\hline İş Güvenliği & 949 & 6,33 & 7,00 & 1,281 \\
\hline Denge & 949 & 6,31 & 7,00 & 1,237 \\
\hline Süpervizör & 949 & 6,37 & 7,00 & 1,267 \\
\hline Yerine Getirilmesi & 949 & 5,74 & 6,00 & 1,469 \\
\hline Ahlaki Değerler & 949 & 6,09 & 7,00 & 1,492 \\
\hline Gelişme/Gelişim & 949 & 6,09 & 7,00 & 1,469 \\
\hline Ücret & 949 & 6,27 & 7,00 & 1,355 \\
\hline Prestij & 949 & 5,30 & 6,00 & 1,788 \\
\hline Tanınma & 949 & 6,10 & 7,00 & 1,394 \\
\hline Seyahat & 949 & 4,68 & 5,00 & 2,355 \\
\hline Becerileri Kullanma & 949 & 5,36 & 6,00 & 1,856 \\
\hline Çeşitlilik & 949 & 5,30 & 6,00 & 1,707 \\
\hline Fiziksel Şartlar & 949 & 6,05 & 7,00 & 1,378 \\
\hline
\end{tabular}

Türkiyede beyaz yakalılarda diğer iş değerlerine göre fazla önem verilen madde "adalet"dir $(6,40)$. Verilen önem açısından bu iş değeri maddesini supervisor $(6,37)$, iş güvenliği $(6,33)$ ve başarı $(6,30)$ izlemektedir. "Seyahat", Türkiyede beyaz yakalılarda diğer iş değerlerine göre en az önem verilen maddedir $(4,68)$. Aynı madde, standart sapması diğer değişkenlere göre en yüksek olan maddedir $(s=2,355)$. Bu konuda katılımcıların düşüncelerinin diğer iş değerleri maddelerine göre en fazla değişkenlik gösterdiği söylenebilir. Standart sapması en düşük olan iş değeri maddesi ise başarıdır $(s=1,137)$. Bu konuda katılımcıların düşüncelerinin diğer iş değerleri maddelerine göre en az değişkenlik gösterdiği söylenebilir.

2 bağımsız grup için birden fazla değişkenin ortalamaları karşılaştırılacaksa parametrik tekniklerden Hotelling $\mathrm{T}^{2}$ ye başvurulabilir. Test bulgularına güvenebilmek için dağılımın çok değişkenli Normal dağılıma uygun olması, iki grubun kovaryans matrislerinin eş olması ayrıca değişkenlerin bağımsız olmaları gerekmektedir.

\subsection{Kușaklara Göre İș Değerleri}

Çok değişkenli Normallik için öncelikle tekli Normallik incelemesi yapılmıştır. Faktör skorları için Kolmogorov Smirnov testi anlamlılık değeri 0,05’ten küçük çıkmıştır. Dolayısıyla parametrik testler için gerekli olan Normallik varsayımı sağlanmamaktadır. Homojenlik varsayımı olarak bilinen $\mathrm{k}$ grubun eş kovaryans matrisine sahip olması varsayımı incelemesini de gerçekleştirilmiş (Box’s M Testi), ilgili varsayımın da sağlanmadığı görülmüştür (Box’s M=47,234; F:7,844; Sig.:0,000). Bu bulgu Levene Testi ile de desteklenmiştir (Faktör 1 sig. 0,168; Faktör 2 sig. 0,689; Faktör 3 sig. 0,000). 
Bu şartlar altında parametrik Hotelling $\mathrm{T}^{2}$ testi yerine, parametrik olmayan tekniklere başvurmak daha sağlıklı bir yol olacaktır. Dolayısıyla 2 grubun konum parametrelerini karşılaştırmak için Mann Whitney U testinden yararlanılmıştır. Ayrıca temel varsayımlar altında parametrik Hotelling $\mathrm{T}^{2}$ uygulaması da gerçekleştirerek, elde edilen sonuçların parametrik olmayan analiz sonuçları ile örtüştüğü teyit edilmiş olup bu uygulamaya ilişkin temel çıktı Ekler’de yer almaktadır.

Türkiye'de beyaz yakalılarda X ve Y kuşağına göre iş değerleri farklılaşıp farklılaşmadığına ilşkin olarak Tablo 3'de test bulguları görülmektedir.

Tablo 3: Mann Whitney U Testi Bulguları

\begin{tabular}{|c|c|c|}
\hline & Sig. & Karar \\
\hline İçsel değerler &, 000 & $\mathrm{H}_{0}$ red \\
\hline Dışsal ve Özgürlük ile ilgili değerler &, 000 & $\mathrm{H}_{0}$ red \\
\hline Sosyal değerler &, 000 & $\mathrm{H}_{0}$ red \\
\hline
\end{tabular}

Görüldüğü gibi 3 faktör için de X ve Y kuşakları arasında anlamlı farklılık gözlenmiştir. Detaylı yorumlamaya olanak tanıyan kuşaklara göre faktör skorları ortalama değerleri ise Tablo 4’te görülmektedir.

Tablo 4: Kuşaklara Göre İş Değerleri Faktörleri Tanımsal İstatistikleri

\begin{tabular}{|l|l|c|c|}
\hline \multicolumn{2}{|l|}{ Değerler } & Ortalama & Standart Sapma \\
\hline \multirow{2}{*}{ Sosyal değerler } & $\mathrm{y}$ & 0,250 & 0,837 \\
\cline { 2 - 4 } & $\mathrm{x}$ & $-0,382$ & 1,103 \\
\hline \multirow{2}{*}{ İçsel değerler } & $\mathrm{y}$ & 0,107 & 1,016 \\
\cline { 2 - 4 } & $\mathrm{x}$ & $-0,163$ & 0,952 \\
\hline \multirow{2}{*}{ Dişsal ve Özgürlük ile ilgili değerler } & $\mathrm{y}$ & 0,085 & 1,004 \\
\cline { 2 - 4 } & $\mathrm{x}$ & $-0,131$ & 0,979 \\
\hline
\end{tabular}

Y kuşağı sosyal iş değeri faktör skoru X kuşağına göre daha yüksek bir değer olarak elde edilmiştir. İçsel ve statü ile ilgili iş değerleri faktör skoru ortalaması Y kuşağında X kuşağına göre daha yüksektir. Dışsal ve özgürlük ile ilgili iş değerleri faktörü için de daha yüksek faktör skoru ortalaması yine Y kuşağına aittir. Analiz maddeleri detaylandırıldığında yalnızca yaratıcılık, etkileme ve seyahat değerleri açısından X ve Y kuşağı arasında anlamlı farka rastlanmamıştır.

Ayrıca faktör skorları ile yaş arasında ilişki olup olmadığı da parametrik olmayan Spearman korelasyon katsayısı yardımıyla incelenmiş olup, yaş ile tüm iş değerleri faktörleri arasında anlamlı ilişkiler bulunduğu saptanmıştır. İlgili çıktı Ek 2'de yer almaktadır.

\subsection{Cinsiyete Göre İş Değerleri}

Normal dağılım göstermeyen veri setine bir önceki bölüm uygulamasına benzer şekilde t Testi’nin parametrik olmayan alternatifi olan Mann Whitney U testi yapılmıștır. Analiz sonucunda sig. 1, 
2, $3=0,000$ olduğundan cinsiyet açısından içsel ve statüsel, dışsal ve özgürlük ile ilgili ve sosyal iş değerlerinin faktörü bakımlarından anlamlı farklılık gözlenmiştir. Sözkonusu istatistiksel olarak anlamlı bu farklılığın cinsiyete göre ortalamaları tabloda görüldüğü gibidir:

Tablo 5: Cinsiyete Göre İş Değerleri Faktörleri Ortalama Değerleri

\begin{tabular}{|c|c|c|}
\hline Faktörler & Kadın (Ortalama) & Erkek (Ortalama) \\
\hline İcsel değerler & 0,288 & $-0,167$ \\
\hline Dışsal ve Özgürlük ile ilgili değerler & 0,232 & $-0,132$ \\
\hline Sosyal değerler & 0,323 & $-0,187$ \\
\hline
\end{tabular}

Genel olarak bakıldığında kadınların erkeklere kıyasla iş değerlerine daha fazla önem verdikleri (ortalamaları daha yüksektir), dolayısıyla ilgili konularda daha hassas oldukları söylenebilir. Analiz maddeleri detaylandırıldığında yalnızca otorite, yalnız çalışma ve seyahat değerleri açısından cinsiyete göre anlamlı farka rastlanmamıştır.

Son olarak X ve Y kuşakları çalışanlarının cinsiyet farklılıklarına baktığımızda detaylar Tablo 6'da görülmektedir.

Tablo 6: Mann Whitney U Testi Bulgular1 - Faktör Skorları

\begin{tabular}{|c|c|c|}
\hline & Sig. & Karar \\
\hline İçsel değerler &, 817 & $\mathrm{H}_{0}$ red \\
\hline Dışsal ve Özgürlük ile ilgili değerler &, 164 & $\mathrm{H}_{0}$ red \\
\hline Sosyal değerler &, 003 & $\mathrm{H}_{0}$ red \\
\hline
\end{tabular}

Görüldüğü gibi 3. faktör olan sosyal iş değerleri faktörü için beyaz yakalı kadınlarda X ve Y kuşakları arasında anlamlı farklılık gözlenmiştir. Kuşaklara göre faktör skorları ortalama değerleri Tablo 7’de görülmektedir.

Tablo 7: Kuşaklara Göre Beyaz Yakalı Kadınlarda Sosyal İş Değeri Faktörü Tanımsal İstatistikleri

\begin{tabular}{|l|l|c|c|}
\hline \multicolumn{2}{|c|}{} & Ortalama & Std. Sapma \\
\hline \multirow{2}{*}{ Sosyal değerler } & $\mathrm{y}$ & 0,383 & 0,679 \\
\cline { 2 - 4 } & $\mathrm{x}$ & 0,087 & 0,986 \\
\hline
\end{tabular}

Y kuşağına mensup beyaz yakalı kadınlarda sosyal iş değerleri faktör skoru, $\mathrm{X}$ kuşağına mensup beyaz yakalı kadınlara göre daha yüksek bir değer olarak elde edilmiştir. Y kuşağı iş arkadaşları ve eğlence gibi sosyalleştiği iş değerlerine $\mathrm{X}$ kuşağına göre daha fazla önem vermektedir.

Maddeler açısından da aynı araştırma sorusu incelenmiş, öncelikle Normallikler araştırılmış ve yine Normal dağılımın sözkonusu olmadığı görülmüştür. Beyaz yakalı kadınlarda kuşaklara göre anlamlı farklılık gözlenen maddelerin aşağıdaki gibi olduğu saptanmıştır. 
Tablo 8: Mann Whitney U Testi Bulguları - Maddeler

\begin{tabular}{|c|c|c|}
\hline & Sig. & Karar \\
\hline Otonomi & 0,026 & $\mathrm{H}_{0}$ red \\
\hline Yetki & 0,022 & $\mathrm{H}_{0}$ red \\
\hline İş arkadaşları & 0,010 & H0 red \\
\hline Eğlenme & 0,006 & H0 red \\
\hline Sürekli öğrenme & 0,016 & H0 red \\
\hline Çalışma saatleri & 0,049 & H0 red \\
\hline Gelişim & 0,015 & H0 red \\
\hline Fiziksel Şartlar & 0,026 & H0 red \\
\hline
\end{tabular}

Otonomi, yetki, iş arkadaşları, eğlenme, sürekli öğrenme, çalışma saatleri, gelişme ve fiziksel şartlar değerleri açısından X ve Y kuşaklarını kadın mensupları farklılaşmaktadır. Daha detaylı görebilmek için kuşaklara göre madde skorları ortalama değerleri Tablo 9’da görülmektedir.

Tablo 9: Kuşaklara Göre Beyaz Yakalı Kadınlarda Social İş Değeri Faktörü Tanımsal İstatistikleri

\begin{tabular}{|l|l|c|c|}
\hline \multicolumn{2}{|l|}{} & Ortalama & Std. Sapma \\
\hline \multirow{2}{*}{ Otonomi } & $Y$ & 6,58 & 0,841 \\
\cline { 2 - 4 } & $\mathrm{X}$ & 6,10 & 1,712 \\
\hline \multirow{2}{*}{ Yetki } & $\mathrm{Y}$ & 6,31 & 1,204 \\
\cline { 2 - 4 } & $\mathrm{X}$ & 5,84 & 1,742 \\
\hline \multirow{2}{*}{ İş Arkadaşları } & $\mathrm{Y}$ & 6,33 & 1,225 \\
\cline { 2 - 4 } & $\mathrm{X}$ & 6,00 & 1,414 \\
\hline \multirow{2}{*}{ Eğlence } & $\mathrm{Y}$ & 6,39 & 0,999 \\
\cline { 2 - 4 } & $\mathrm{X}$ & 5,90 & 1,552 \\
\hline \multirow{2}{*}{ Sürekli Öğrenme } & $\mathrm{Y}$ & 6,53 & 1,018 \\
\cline { 2 - 4 } & $\mathrm{X}$ & 6,24 & 1,148 \\
\hline \multirow{2}{*}{ Çalışma Saatleri } & $\mathrm{Y}$ & 6,44 & 1,166 \\
\cline { 2 - 4 } & $\mathrm{X}$ & 6,20 & 1,410 \\
\hline \multirow{2}{*}{ Gelişim } & $\mathrm{Y}$ & 6,51 & 1,164 \\
\cline { 2 - 4 } & $\mathrm{X}$ & 6,14 & 1,600 \\
\hline \multirow{2}{*}{ Fiziksel Şartlar } & $\mathrm{Y}$ & 6,40 & 1,211 \\
\cline { 2 - 4 } & $\mathrm{X}$ & 6,19 & 1,146 \\
\hline
\end{tabular}

Genel olarak bakıldığında Y kuşağı beyaz yakalı kadınların, X kuşağı beyaz yakalı kadınlara kıyasla otonomi, yetki, iş arkadaşları, eğlence, sürekli öğrenme, çalışma saatleri, gelişim ve fiziksel şartlar iş değerlerine daha fazla önem verdikleri (ortalamaları daha yüksektir), dolayısıyla ilgili konularda daha duyarlı oldukları söylenebilir.

\section{Sonuç ve Tartışma}

Bu çalışma ile X ve Y kuşaklarının iş değerleri açısından farklılaşıp farklılaşmadı̆̆ı, farklılaşıyor ise farklılaşmanın yapısı analiz edilmiştir. Çalışma kapsamında 949 birimlik geniş bir örneklem 
ile çalışılmıştır. Türkiye'de beyaz yakalılarda kuşaklara göre iş değerleri farklılık analiz sonuçları şu şekilde özetlenebilir:

Türkiyede beyaz yakalılarda diğer iş değerlerine göre fazla önem verilen madde "adalet"tir $(6,40)$. Verilen önem açısından bu iş değeri maddesini süpervizör $(6,37)$, iş güvenliği $(6,33)$ ve başarı $(6,30)$ izlemektedir. Ekonomik şartlar, işsizlik oranları, genç nitelikli nüfusun fazlalığı ve her iki kuşağında karakteristik özellikleri dikkate alındığında önem verilen iş değerleri şaşırtıcı değildir. "Seyahat", Türkiyede beyaz yakalılarda diğer iş değerlerine göre en az önem verilen maddedir $(4,68)$. Aynı madde, standart sapması diğer değişkenlere göre en yüksek olan maddedir $(s=2,355)$. Bu konuda katılımcıların düşüncelerinin diğer iş değerleri maddelerine göre en fazla değişkenlik gösterdiği söylenebilir. Standart sapması en düşük olan iş değeri maddesi ise başarıdır ( $(s=1,137)$. Bu konuda katılımcıların düşüncelerinin diğer iş değerleri maddelerine göre en az değişkenlik gösterdiği söylenebilir.

Genişörnekle yapılan kuşaklar arası iş değerler analizi sonuçlarına bakıldığında; içsel, dışsal ve sosyal iş değerlerinden oluşan 3 faktörlü bir yapı ortaya çımıştır. Her üç iş değeri faktöründe de Y kuşağı istatistiki anlamlı olarak X kuşağından daha yüksek düzeyde sahip olduğu tespit edilmiştir. Bulgular maddeler bazında detaylandırılmak istenmiş, analiz maddelerinin orijinal halleri de kullanılarak uygulama tekrar edilmiş, sonuç olarak yaratıcılık, etkilenme, seyahat değişkenleri açısından $\mathrm{X}$ ve $\mathrm{Y}$ kuşağı arasında anlamlı farka rastlanmadığı (diğer iş değerleri maddelerinde ise Y kuşağı ortalama değerlerinin ortalamasının daha yüksek olduğu) ek bulgusuna ulaşılmıştır.

Çalışma kapsamında Türkiyede beyaz yakalılarda cinsiyete göre iş değerlerinin farklılaşıp farklılaşmadığı dair sonuçlara bakıldığında kadınların erkeklere kıyasla iş değerlerine daha fazla önem verdikleri (ortalamaları daha yüksektir), dolayısıyla ilgili konularda daha önem verdikleri görülmektedir. Başka deyişle, kadınlar iş değerlerine sahip olma derecesi her bir faktör için erkeklerden daha yüksektir. Otorite, yalnız çalı̧̧ma ve seyahat iş değerleri özelinde ise cinsiyete göre (anlamlı) farklılık olmadığı bulgusuna ulaşılmıştır.

Analiz sonucunda $\mathrm{Y}$ kuşağına mensup beyaz yakalı kadınlarda social iş değeri faktör skoru, $\mathrm{X}$ kuşağına mensup beyaz yakalı kadınlara göre (önemli düzeyde) daha yüksek bir değer olarak elde edilmiştir. Maddeler bazında ise y kuşağı beyaz yakalı kadınların, x kuşağı beyaz yakalı kadınlara kıyasla otorite, yetki, iş arkadaşları, eğlence, sürekli öğrenme, çalışma saatleri, gelişim ve fiziksel şartlar iş değerlerine daha fazla önem verdikleri ek bulgusuna ulaşılmıştır.

Y kuşağına mensup beyaz yakalı kadınlarda sosyal iş değerleri faktör skoru, $\mathrm{X}$ kuşağına mensup beyaz yakalı kadınlara göre daha yüksek bir değer olarak elde edilmiştir. Y kuşağı iş arkadaşları ve eğlence gibi sosyalleştiği iş değerlerine $\mathrm{X}$ kuşağına göre daha fazla önem vermektedir. Bu bağlamda Y kuşağı çalışanları işe çekmek ve motivasyonları yüksek şekilde istihdam ettirebilmek istiyorsak sosyal faaliyetlere daha fazla önem verilmesi gerekliliği ortaya çımmaktadır.

Çalışanların sahip oldukları iş değerlerini anlamak, eğer motivasyonlarını ve dolayısıyla performanslarını yükseltmek ve motivasyonu yüksek çalışanları çekmek isteniyorsa, örgütün nasıl bir iş yapısı, çalışma koşulları, ücret ve yan hak paketleri ve insan kaynağı politikaları yaratmaları 
gerekliliği hakkında fikir vermektedir.Yeni seçme ve işe alma yöntemleri, çalışan çekme yöntemlerini değiştirilmeli, eski yöntemler ve İK politikaları yerine yeni kuşakların eğitim ve geliştirme stratejileri, kariyer geliştirme yöntemleri ve iş koşullarının yaratılması gerekmektedir.

Entelektüel sermayenin çeşitlendiği ve farklılıklar ile zenginleştiği, iç müşteri olarak görülen çalışanların önemli bir insan sermayesi olduğu günümüz işletmelerinde her nesli daha iyi anlamak ve onların birlikte çalışmalarını sağlamak için kuşakları ve sahip oldukları iş değerlerini bilmek gereklilik haline gelmiştir. ${ }^{31}$ Ancak kuşaklar hakkında çıkarım ve önerilerde bulunurken Türk toplumunda büyüyen ve çalışan Y kuşağının özellikleri, beklentileri, iş değerleri, motivasyon kaynakları ile ilgili olarak yabancı yazından ziyade Türkiye çalışan örnekleminde yapılan çalışmalar dikkate alınması gerekliliği gözden kaçmamalıdır. Demirkaya ve diğerleri (2015) ${ }^{32}$ yaptıkları araştırma sonuçları da Türkiye kuşaklarının özellikleri yabancı ülke kuşak çalışanlarından farklılaşabildiği yönündedir.

\section{Kaynakça}

BAYAR, L. (2016). Demografik Faktörlerin İş Değerleri Üzerine Etkisi; İşçi Sendikaları Üzerine Bir Araştırma. Adnan Menderes Üniversitesi Sosyal Bilimler Enstitüsü Dergisi, 3(1), 38-67.

CHERRINGTON, D. J., Condie, S. J., \& England, J. L. (1979). Age Work Values. Academy of Management Journal, 22(3), 617-623.

DAFT, R.L. (2007). Management, The Dryden Press, 10.Baskı.

DEMİRKAYA, H., Akdemir, A., Karaman, E., \& Atan, Ö. (2015). Kuşakların yönetim politikası beklentilerinin araştırılması, İşletme Araştırmaları Dergisi, 7(1): 186-204.

EISNER, S. P. (2005). Managing generation Y, SAM Advanced Management Journal, 70(4): 4-15.

FERNANDES, K., Hyde, A., Ives, S., Fleischer, S., Evoy, T., \& Van Marrum, K. (2012). A Comparative Study of Work Values between Generation X and Generation Y. Unpublished manuscript, University of Guelph.

FURNHAM, A., Petrides, K. V., Tsaousis, I., Pappas, K., \& Garrod, D. (2005). A Cross-Cultural İnvestigation Into The Relationships Between Personality Traits And Work Values. The Journal of Psychology, 139(1), 5-32.

GREENWOOD R.A., Gibson, J.W., Murphy, Jr. E.F. (2008). An Investigation of Generational Values in the Workplace: Divergence, Convergence, and Implications for Leadership, International Leadership Journal, 1(1): 57-77.

HO, J.A. 2010. Ethical Perception: Are Differences Between Ethnic Groups Situation Dependent?, Business Ethics: A European Review, April, 19(2): 154-182.

LI, W., Liu, X., \& Wan, W. (2008). Demographic Effects Of Work Values And Their Management Implications. Journal of Business Ethics, 81(4), 875-885.

LOUGHLIN, C., Barling, J. (2001). Young workers' work values, attitudes, and behaviours, Journal of Occupational and Organizational Psychology, 74, 543-558.

LYONS, S. L. Duxbury, C. Higgins (2005). An empirical assessment of generational differences in work-related values, Human Resource Management, 26: 62-71.

MARTIN, C., \& Tulgan, B. (2002). Managing the generation mix: From collision to collaboration. Amherst, MA: HRD Press.

31 Wilson, L. (2009). Workforce diversity - generations at work: The problems, power, and promise explored. American Water Works Association Journal, 101(5), 46-54.

32 Demirkaya ve diğerleri, 2015. 
NG, E.S.W., Schweitzer, L., Lyons, S.T. (2010). New Generation, Great Expectations: A Field Study of the Millennial Generation, Journal of Business and Psychology, Special Issue: Millennials and the World of Work: What You Didn't Know You Didn't Know, 25(2): 281-292.

PARRY, E., Urwin, P. (2011). Generational Differences in Work Values: A Review of Theory and Evidence, International Journal of Management Reviews, 13(1): 79-96.

RYAN, R. M., Deci, E. J. (2000). Self-determination theory and the facilitation of intrinsic motivation, social development, and well-being. American Psychologist, 55: 68-78.

SAGIE, A., Elizur, D., \& Koslowsky, M. (1996). Work Values: A Theoretical Overview and A Model Of Their Effects. Journal of Organizational Behavior, 17(1): 503-514.

SARUHAN, S.C., M.L. Yıldız 2014. İnsan Kaynakları Yönetimi: Teori ve Uygulama, Beta Yayınları, 2.Baskı.

SÜRAL-ÖZER, P., Eriş, E. D., \& Timurcanday-Özmen, Ö. N. (2013). Kuşakların Farklılaşan İş Değerlerine İlişkin Emik Bir Araştırma. Dumlupınar Üniversitesi Sosyal Bilimler Dergisi, 38(38), 123-142.

ŞENTURAN, Ş., Köse, A., Dertli, E., Başak, S., \& Şentürk, N. (2016). X ve Y Kuşağı Yöneticilerinin İş Değerleri Alg1sı ve Farklılıkları Üzerine İnceleme. Business \& Economics Research Journal, 7(3): 171-182.

TWENGE, J.M. (2010). A Review of the Empirical Evidence on Generational Differences in Work Attitudes, Journal of Business and Psychology, 25(2): 201-210.

TWENGE, J.M., Campbell, S.M. (2012). Chapter 1: Who are the Millennials? Empirical evidence for generational differences in work values, attitudes and personality, Eddy S. Ng, Sean Lyons and Linda Schweitzer (2012). Managing the New Workforce International Perspectives on the Millennial Generation içinden.

TWENGE, J.M., Campbell, S.M., Hoffman, B.J., Lance, C.E. (2010). Generational difference in work values: Leisure and extrinsic values increasing, social and intrinsic values decreasing, Journal of Management, 36: $1117-1142$.

WİLSON, L. (2009). Workforce diversity - generations at work: The problems, power, and promise explored. American Water Works Association Journal, 101(5), 46-54.

YAZICIOĞLU, Y., Erdoğan, S. 2004. SPSS Uygulamalı Bilimsel Araştırma Yöntemleri, Ankara: Detay Yayıncılık.

ZEMKE, R., C. Raines, B. Filipczak 1999. Generations at Work: Managing the Clash of Veterans, Boomers, Xers, and Nexters in Your Workplace, Amacom. 
EK 1: Normallik, Homojenlik ve Bağımsızlık Varsayımı Altında Uygulanan Hotelling $\mathrm{T}^{2}$ Testi SPSS Çıktıları

Çok Değișkenli Testler

\begin{tabular}{|ll|r|r|r|r|r|}
\hline Etki & & Değer & \multicolumn{1}{c|}{ F } & Hipotez sd & Hata sd & \multicolumn{1}{c|}{ Sig. } \\
\hline \multirow{4}{*}{ Sabit } & Pillai's Trace &, 005 & $1,477^{\mathrm{b}}$ & 3,000 & 945,000 &, 219 \\
& Wilks' Lambda &, 995 & $1,477^{\mathrm{b}}$ & 3,000 & 945,000 &, 219 \\
& Hotelling's Trace &, 005 & $1,477^{\mathrm{b}}$ & 3,000 & 945,000 &, 219 \\
& Roy's Largest Root &, 005 & $1,477^{\mathrm{b}}$ & 3,000 & 945,000 &, 219 \\
\hline \multirow{4}{*}{ Yaşkategorik } &, 096 & $33,596^{\mathrm{b}}$ & 3,000 & 945,000 &, 000 \\
& Pillai's Trace &, 904 & $33,596^{\mathrm{b}}$ & 3,000 & 945,000 &, 000 \\
& Wilks' Lambda &, 107 & $33,596^{\mathrm{b}}$ & 3,000 & 945,000 &, 000 \\
& Hotelling's Trace &, 107 & $33,596^{\mathrm{b}}$ & 3,000 & 945,000 &, 000 \\
\hline
\end{tabular}

Levene's Test of Equality of Error Variances ${ }^{\mathrm{a}}$

\begin{tabular}{|c|c|c|c|c|}
\hline & $\mathrm{F}$ & df1 & df2 & Sig. \\
\hline INSTRINSICSTATUSNF1 & 1,904 & 1 & 947 & , 168 \\
\hline EXTRINSICFREEDOMNF2 & ,160 & 1 & 947 & ,689 \\
\hline SOCIALNF3 & 38,653 & 1 & 947 &, 000 \\
\hline
\end{tabular}

EK 1: Normallik, Homojenlik ve Bağımsızlık Varsayımı Altında Uygulanan Hotelling $\mathrm{T}^{2}$ Testi SPSS Çıktıları - Devam

\begin{tabular}{|c|c|c|c|c|c|c|}
\hline \multicolumn{7}{|c|}{ Tests of Between-Subjects Effects } \\
\hline Kaynak & Bağımlı Değiş̧ken & $\begin{array}{c}\text { Tip III Kareler } \\
\text { Toplamı }\end{array}$ & sd & $\begin{array}{c}\text { Kareler } \\
\text { Ortalaması } \\
\end{array}$ & $\mathrm{F}$ & $\begin{array}{l}\text { Kuyruk } \\
\text { Olasilığ } 1 \\
\end{array}$ \\
\hline \multirow[b]{3}{*}{$\begin{array}{l}\text { Corrected } \\
\text { Model }\end{array}$} & INSTRINSICSTATUSNF1 & $16,658^{\mathrm{a}}$ & 1 & 16,658 & 16,938 & 0 \\
\hline & EXTRINSICFREEDOMNF2 & $10,668^{\mathrm{b}}$ & 1 & 10,668 & 10,778 & 0,001 \\
\hline & SOCIALNF3 & $90,825^{\mathrm{c}}$ & 1 & 90,825 & 100,343 & 0 \\
\hline \multirow[b]{3}{*}{ Intercept } & INSTRINSICSTATUSNF1 & 0,732 & 1 & 0,732 & 0,745 & 0,388 \\
\hline & EXTRINSICFREEDOMNF2 & 0,469 & 1 & 0,469 & 0,474 & 0,491 \\
\hline & SOCIALNF3 & 3,994 & 1 & 3,994 & 4,412 & 0,036 \\
\hline \multirow{3}{*}{ yaşkategorik } & INSTRINSICSTATUSNF1 & 16,658 & 1 & 16,658 & 16,938 & 0 \\
\hline & EXTRINSICFREEDOMNF2 & 10,668 & 1 & 10,668 & 10,778 & 0,001 \\
\hline & SOCIALNF3 & 90,825 & 1 & 90,825 & 100,343 & 0 \\
\hline
\end{tabular}


EK 2: Analizler Spearman Korr. Kats. İle de Desteklenmiş Olup Bulgular Aşağıda Özetlenmiştir. (Yaş ve Faktör Skorları Arasındaki Anlamlı İlişkiler)

\begin{tabular}{|c|c|c|c|}
\hline \multicolumn{4}{|l|}{ Correlations } \\
\hline & & & yaş \\
\hline \multirow{12}{*}{ Spearman's rho } & \multirow{3}{*}{ yaş } & Correlation Coefficient & 1,000 \\
\hline & & Sig. (2-tailed) & . \\
\hline & & $\mathrm{N}$ & 949 \\
\hline & \multirow{3}{*}{ INSTRINSICSTATUSNF1 } & Correlation Coefficient &,- 149 \\
\hline & & Sig. (2-tailed) &, 000 \\
\hline & & $\mathrm{N}$ & 949 \\
\hline & \multirow{3}{*}{ EXTRINSICFREEDOMNF2 } & Correlation Coefficient &,- 186 \\
\hline & & Sig. (2-tailed) &, 000 \\
\hline & & $\mathrm{N}$ & 949 \\
\hline & \multirow{3}{*}{ SOCIALNF3 } & Correlation Coefficient &,- 320 \\
\hline & & Sig. (2-tailed) &, 000 \\
\hline & & $\mathrm{N}$ & 949 \\
\hline
\end{tabular}




\section{Extended Abstract}

Nowadays, businesses have become an environment where three or even four generations work together. In the past, many generations worked together in the same workplace. However, they were in different job definitions and a different system hierarchy. Middle age employees tended to be mid-level managers, while younger employees worked in the remaining positions. The interactions of these generations were generally in the form of superior-subordinate relationship. However, the change of competencies needed along with the development of technology reorganized hierarchical systems based on age and seniority. They started communicating and working together in different generations in a different way than ever before. In addition, human resources management strategies aim to attract employees of all ages or generations of strategic importance for job applications, create loyalty after work and ensure that they remain in work.

Generation refers to a group of people in a similar age group who have experienced similar social events in an similar geography. The generations theory explains the change of people's values, attitudes and beliefs with social changes, important historical events among the generations. Values affect attitudes, attitudes affect behavior. Therefore, if generations have different value systems, it is important to understand them as employees will develop attitudes and behaviors based on these values. Business value refers to the employee's expectations and feelings about the job. Although discussions on the difference between business values and general values continue, the most accepted classification of business values are extrinsic, intrinsic, lieseru, social and alturistic work values.

When we compare the generations in Turkey, we find small samples or studies on students. In this context, the main purpose of this research is to compare the work values of the $\mathrm{X}$ and $\mathrm{Y}$ Generation employees in a large sample in Turkey. Futhermore, whether business values in Turkey differ according to gender and if they differ, the structure of this difference will also be examined. In this way, it is aimed to indirectly raise the job values profile of the labour force in Turkey (with its outlines). One of the most important contributions of the study to the literature is that it is conducted in a large sample of 949 units in Turkey.

According to analysis results, a 3-factor structure consisting of internal, external\&leisure and social business values has emerged in white collar workers in Turkey. In all three business value factors, Generation Y was statistically significantly higher than Generation X. The findings were detailed on the basis of the items and the application was repeated using the original versions of the analysis items. As a result, there was no significant difference between Generation $\mathrm{X}$ and $\mathrm{Y}$ in terms of creativity, influence, and travel variables (the average of Generation $\mathrm{Y}$ values in other work values items is higher).

On the other hand, when we look at whether job values differ according to gender in white collar workers in Turkey, it is seen that women place more importance on job values than men (their average is higher), so while they put more emphasis on related issues. In other words, women have higher business values than men for each factor. The authority found that there were no (significant) differences in gender in terms of working alone and travelling work values. 
As a result of the analysis, the Social Work Value Factor score was (significantly) higher in white collar women of Generation Y than in white collar women of Generation X. In terms of substances, it was found that white-collar women of Generation X place more emphasis on Autonomy, Competence, Coworkers, Fun, Countinuoslylearn, Hourofwork, Advancement and Physical setting work values than white-collar women of Generation x.

In white collar women of Generation Y, The Social Work Values factor score was higher than in white collar women of Generation X. Generation Y pays more attention to the business values they socialize with, such as co-workers and entertainment, than Generation X / Generation Y places more emphasis on the business values that they socialize with, such as colleagues and fun, than generation X. In this context, if we want to attract Generation Y employees and employ them with high motivation, it is necessary to give more importance to social activities.

If the employers want to increase employees' motivation and therefore their performance and attract highly motivated employees, understanding the business values of the employees gives an idea about what kind of business structure, working conditions, wage and benefits packages and human resource policies should be created. New recruitment and selection methods, employee retention methods should be changed, training and development strategies of new generations, career development methods and job conditions should be created instead of old methods and HR policies.

In today's businesses, where intellectual capital is diversified and enriched with diversity and employees who are considered as internal customers is an important human capital, it has become necessary to know the generations and the business values they have in order to better understand each generation and enable them to work together. However, when making inferences and suggestions about the generations, the characteristics, expectations, business values and motivational sources of the growing and working Generation Y in Turkish society should be taken into consideration in the Turkish employee sample rather than the foreign literature. The result of research conducted by Demirkaya et al (2015) is that the characteristics of Turkey generations can be differentiated from those of foreign country generations.

Generational differences in work values influence recruitment training and development, career development, rewards and working arrangements, and also HR policies. As a result of these supposed generational differences in workplace, managers need to advice on how best to manage generational differences at work. 